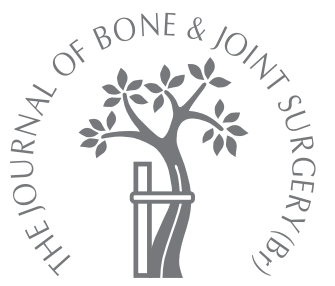

- ANNOTATION

\title{
Key factors for a successful National Arthroplasty Register
}

\author{
C. Kolling, \\ B. R. Simmen, \\ G. Labek, \\ J. Goldhahn \\ From Schulthess \\ Clinic, Zürich, \\ Switzerland
}

- C. Kolling, MD, Research Fellow

B. R. Simmen, $M D_{\text {, }}$

Orthopaedic Surgeon,

Chairman of Upper Extremity

and Hand Surgery

(E. J. Goldhahn, MD, Senior

Researcher

Schulthess Clinic, Lengghalde

2, 8008 Zürich, Switzerland.

= G. Labek, MD, Orthopaedic Surgeon, Co-ordinator, Vice Chairman and EFFORT-EAR Orthopaedic Department Medical University Innsbruck, Anichstrasse 35, A-6020 Innsbruck, Austria.

Correspondence should be sent to $\mathrm{Dr}$ C. Kolling; e-mail: christoph.kolling@kws.ch

(C2007 British Editorial Society of Bone and Joint Surgery doi:10.1302/0301-620X.89B12. $19409 \$ 2.00$

$J$ Bone Joint Surg $[\mathrm{Br}]$ 2007;89-B:1567-73.

\begin{abstract}
Since the introduction of the first National Arthroplasty Register in Sweden in 1975, many other countries have tried to adopt the successful Scandinavian system. However, not all have overcome the political and practical difficulties of establishing a working register. We have surveyed the current registries to establish the key factors required for an effective database. We have received detailed information from 15 arthroplasty registers worldwide. The legal conditions under which they operate together with the methods of collection and handling of the data differ widely, but the fulfilment of certain criteria is necessary achieve a high degree of completeness of the data to ensure the provision of statistically relevant information.
\end{abstract}

The first arthroplasty register was introduced in Sweden in $1975 .{ }^{1}$ Other Scandinavian countries followed shortly afterwards (Fig. 1) gathering information regarding survival rates of implant systems used nationwide. By identifying poorly-performing implants or operational procedures, hospitals were able to change their surgical practice and choose the best products for their arthroplasty surgery. As a result, the burden of revision procedures has decreased significantly in Sweden. ${ }^{2}$

Many other countries have tried to adopt the Scandinavian system, but the establishment of a register requires the management of political and practical challenges. ${ }^{3}$ Some countries managed to set up fully working registers within a few years, ${ }^{4,5}$ achieving a high level of completeness of the national data, which is essential for useful and reliable registers. ${ }^{6-8}$ Others have not been able to achieve the same success, with their registers covering only part of such data. ${ }^{9,10}$ The German Arthroplasty Register ${ }^{10}$ had to suspend its work because of the low rate of participation and the resulting financial problems.

What determines the success or the failure of a registry? Malchau et $\mathrm{al}^{11}$ noted that a national identification number plays an important role. Havelin et $\mathrm{al}^{12}$ emphasised the need for a simple reporting system with continuous feedback to the surgeons. However, the Swedish and Norwegian registers have had over two decades to set up their powerful research instruments. For some currently in development, key factors are still missing.
We have carried out an international survey to assess the differences in the various approaches in setting up a national register and to analyse the requirements for the establishment of an effective database as a source for scientific analysis.

\section{Materials and Methods}

Registers established more recently differ considerably in their state of development. We have focused on those considered to be fully operational with an established structure and organisation. Registers might be expected to have a validated completeness of more than $90 \%$ of the national data. However, only a few are yet able to achieve this. We also examined those which had a completed structure but did not have appropriate validation of their data or were not able to collect more than $90 \%$ of this information. Other registries still in development are considered as established but without a fully implemented organisation and structure.

We undertook an extensive literature and web search regarding the organisation, documentation, data handling and output of a register. Subsequently, a standardised questionnaire was sent out to the registers asking them to validate the preliminary information. The questions included the funding of the register, its maintenance, how the data was collected and entered into the database and if the hospitals and public receive regular feedback. The responses were checked, and, if necessary, further information was requested via phone. The answers were categorised and summarised (Tables I and II). 2,4,5,13-18 


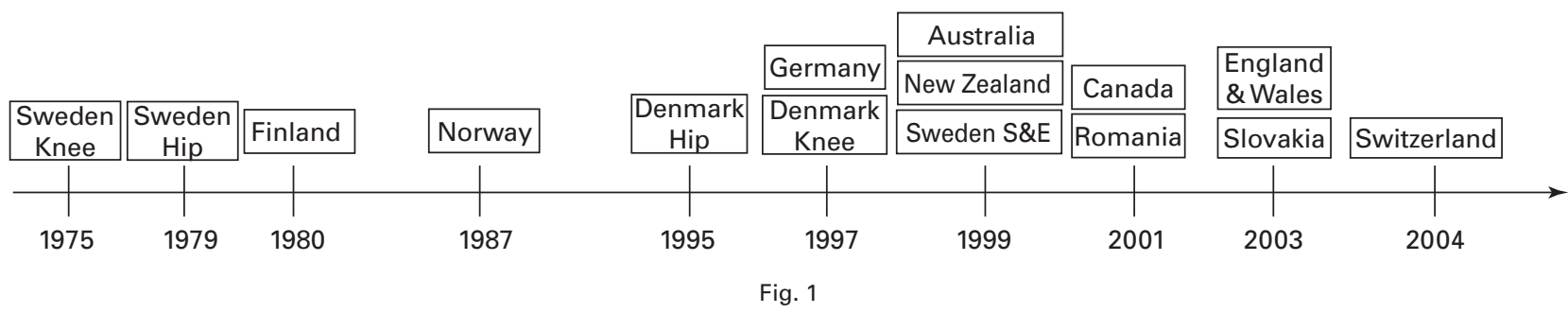

Time line showing the year the registers were established ( $\&$ \& , shoulder and elbow).

Table I. Details of the registries assessed

\begin{tabular}{|c|c|c|c|c|c|c|}
\hline & Maintenance $^{*}$ & Funding $^{\dagger}$ & Participation obligatory $^{\ddagger}$ & Nationwide patient ID & Patient consent & Literature reference \\
\hline Australia & A & G & - & + & - & 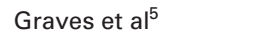 \\
\hline Canada & G & G & - & + & + & Bourne $e^{13}$ \\
\hline \multicolumn{7}{|l|}{ Denmark } \\
\hline Hip & A & G & + & + & - & Lucht $^{4}$ \\
\hline Knee & $A$ & G & + & + & + & $\mathrm{N} / \mathrm{A}^{\pi}$ \\
\hline England/Wales & G & $\mathrm{L}$ & $t^{\S}$ & + & + & $\mathrm{N} / \mathrm{A}$ \\
\hline Finland & G & G & + & + & - & Puolakka et $\mathrm{al}^{8}$ \\
\hline New Zealand & A & $\mathrm{G}, \mathrm{A}$ & - & + & + & Rothwell14 \\
\hline Norway & A & G & - & + & + & Havelin $^{15}$ \\
\hline Romania & A & G & - & + & + & $\mathrm{N} / \mathrm{A}$ \\
\hline Slovakia & A & G & + & + & - & $\mathrm{N} / \mathrm{A}$ \\
\hline \multicolumn{7}{|l|}{ Sweden } \\
\hline Knee & $A$ & G & - & + & - & Robertsson et al ${ }^{16}$ \\
\hline Hip & A & G & - & + & - & Herberts and Malchau ${ }^{2}$ \\
\hline Elbow & A & A & - & + & - & Rahme et al ${ }^{17}$ \\
\hline Shoulder & A & $\mathrm{G}, \mathrm{A}$ & - & + & - & Rahme et al ${ }^{17}$ \\
\hline Switzerland & A & $A^{* *}$ & - & - & - & Röder et al ${ }^{18}$ \\
\hline
\end{tabular}

* A, associations; G, government

$\dagger \mathrm{L}$, levies on implants

$\ddagger+$, yes; - , no

II N/A, not available

$\S$ depends on hospital status

** still pending

\section{Results}

All the 15 arthroplasty registers whom we approached returned the completed questionnaire. They were analysed under the headings of organisation, documentation, data handling and output.

Organisation. The majority of registers are maintained by national orthopaedic associations. Others are driven by government institutions, as in England and Finland, or work in close conjunction with federal health authorities, as in Canada. Most are financially supported by government institutions such as national districts or health agencies. Other funding sources can be by membership fees of the orthopaedic societies as with the Swedish elbow registry, by grants in the case of the Swedish Knee registry or by levies placed on the sale of implants as in England. In several cases, two or more of these sources are needed to balance the annual budget.
The rate of participating hospitals can reach up to $100 \%$, although in most countries participation is voluntary. In Finland, partly in Denmark and in Slovakia, hospitals are required to take part by government decree. In Romania, there is no legal obligation for the hospitals to participate, but they receive financial support from health insurers if they do.

The health systems in most countries offer a unique patient identifier which is assigned to each inhabitant. Only in Switzerland do privacy issues prevent implementation of these unique patient numbers.

The consent of the patient is mandatory in six of the evaluated registries. In Australia, consent is obtained using the 'opt off' approach where patients would have to ask not to be put on the register.

Documentation. Every registry collects data on hip and knee replacements except in Sweden and Denmark where separate databases exist for each joint. Registries in 
Table II. Details of documentation, data input and output

\begin{tabular}{|c|c|c|c|c|c|c|c|c|c|c|c|c|c|}
\hline & \multicolumn{6}{|c|}{ Documentation details* } & \multicolumn{4}{|c|}{ Data input and handling ${ }^{\dagger}$} & \multicolumn{3}{|c|}{ Data output } \\
\hline & $\begin{array}{l}\text { Documented } \\
\text { joint } \\
\text { replacements }\end{array}$ & $\begin{array}{l}\text { Demo- } \\
\text { graphic } \\
\text { details }\end{array}$ & $\begin{array}{l}\text { Operation } \\
\text { details }\end{array}$ & $\begin{array}{l}\text { Patient } \\
\text { questionnaires }\end{array}$ & $\begin{array}{l}\text { Clinical } \\
\text { scores }\end{array}$ & $\begin{array}{l}\text { Radiological } \\
\text { documentation }\end{array}$ & $\begin{array}{l}\text { Documentation } \\
\text { type }\end{array}$ & $\begin{array}{l}\text { CIS } \\
\text { support }\end{array}$ & $\begin{array}{l}\text { Data } \\
\text { validation }\end{array}$ & $\begin{array}{l}\text { Implant } \\
\text { tracking }\end{array}$ & $\begin{array}{l}\text { Report } \\
\text { to the } \\
\text { clinics }\end{array}$ & $\begin{array}{l}\text { Public } \\
\text { reports }\end{array}$ & $\begin{array}{l}\text { Access } \\
\text { to the } \\
\text { database }\end{array}$ \\
\hline Australia & $\mathrm{H}, \mathrm{K}$ & + & + & - & - & - & $P$ & - & $\mathrm{M}, \mathrm{E}$ & + & + & + & - \\
\hline Canada & $\mathrm{H}, \mathrm{K}$ & + & + & - & - & - & $P, D$ & - & $\mathrm{E}$ & - & + & + & - \\
\hline \multirow[t]{2}{*}{ Denmark } & $\mathrm{H}$ & + & + & - & + & - & $P, D$ & - & M & - & + & + & - \\
\hline & $\mathrm{K}$ & + & + & - & + & - & & + & M & & + & - & - \\
\hline $\begin{array}{l}\text { England/ } \\
\text { Wales }\end{array}$ & $\mathrm{H}, \mathrm{K}$ & + & + & - & - & - & W, D & + & $E$ & + & + & + & + \\
\hline Finland & $\mathrm{H}, \mathrm{K}, \mathrm{S}, \mathrm{E}, \mathrm{A}$ & + & + & + & - & - & $\mathrm{P}$ & - & M & & - & + & - \\
\hline $\begin{array}{l}\text { New } \\
\text { Zealand }\end{array}$ & $\mathrm{H}, \mathrm{K}, \mathrm{S}, \mathrm{E}, \mathrm{A}$ & + & + & + & - & - & $\mathrm{P}, \mathrm{W}$ & - & M & + & + & - & - \\
\hline Norway & All & + & + & - & - & - & $P, D$ & - & $\mathrm{M}, \mathrm{E}$ & + & + & + & - \\
\hline Romania & $\mathrm{H}, \mathrm{K}$ & + & + & - & - & + & $\mathrm{P}, \mathrm{W}$ & - & $\mathrm{M}, \mathrm{E}$ & + & + & + & + \\
\hline Slovakia & $\mathrm{H}, \mathrm{K}$ & + & + & - & - & - & W, D & - & $\mathrm{E}$ & - & - & - & + \\
\hline \multirow[t]{4}{*}{ Sweden } & K & + & + & - & - & - & $\mathrm{P}, \mathrm{W}$ & - & $\mathrm{M}$ & + & + & + & + \\
\hline & $\mathrm{H}$ & + & + & - & - & - & $\mathrm{P}, \mathrm{W}, \mathrm{D}$ & - & $\mathrm{M}, \mathrm{E}$ & + & + & + & + \\
\hline & $E$ & + & + & - & - & - & $\mathrm{P}$ & - & $\mathrm{M}$ & - & + & + & - \\
\hline & S & + & + & + & - & - & $\mathrm{P}$ & - & $M$ & - & + & + & - \\
\hline Switzerland & $\mathrm{H}, \mathrm{K}$ & + & + & + & + & + & $\mathrm{P}, \mathrm{W}, \mathrm{O}$ & & $E$ & + & - & - & + \\
\hline
\end{tabular}

* $\mathrm{H}$, hip; K, knee; S, shoulder; E, elbow; A, ankle; +, yes; -, no

† P, paper; D, data file; $W$, web; O, optimal mark reader; $C I S$, clinical information system; $M$, manual; E, electrical

Finland, New Zealand, Norway and Sweden record information on other joints, mainly the shoulder, elbow and ankle, but some also include finger and toe joints.

In general, the dataset consists of patient identifiers, with the name, date of birth and gender, hospital identifiers and basic surgical data including the date of operation, the diagnosis, the surgical procedure and the implants used.

Three registers collect clinical scores as part of the standard registration. Others, such as in Switzerland, offer clinical scores optionally, for example when additional studies are being undertaken. Patient-based questionnaires are included in four registers. In New Zealand, the Oxford hip, knee and shoulder, and non-validated questionnaires for the elbow and ankle, are used for postoperative follow-up. The Swedish shoulder registry has started a five-year follow-up by mailing self-evaluating questionnaires (Western Ontario Osteoarthritis of the shoulder $^{19}$ index, Euroqol-EQ5D). ${ }^{20}$ They have also launched a pilot scheme using the same scores before and one year after operation. The Swedish elbow registry plans to use the Disability of the Arm, Shoulder and Hand score for the five-year follow-ups. ${ }^{21}$ In Romania and Switzerland information concerning the radiological findings are collected as part of the post-operative followup.

Data handling. The registries offer one or more method of documentation and the hospitals can choose which is the most suitable for their daily routine. The paper-based method is available in nearly every register while online access or other types of electronic data transfer is not offered by all.
Only in England do hospitals have to use electronic systems to transfer the collected data; either via a web interface or using the bulk upload facility. Paper forms can be used as proformas, helping to collect the required information before being entered electronically.

The extraction of data from the hospital or theatre information systems is only offered by two registers, although other registers are conducting trials of this method and will offer it as standard procedure in the near future.

Details of the implant can be documented in different ways. Either the information is obtained by manually marking the corresponding category in a given list of attributes or it can be integrated into the theatre information system by using the implant tracking method.

Outcome. Surgeons receive regular feedback from the registers in nearly all countries and results are published as annual reports or scientific articles in orthopaedic journals. Only a few registers allow surgeons online access to their data.

\section{Discussion}

Organisation. Who should be responsible for the maintenance of a register; the government or the national orthopaedic association? The survey showed that national registries can be successfully maintained by either the orthopaedic association or the providers of health care, but full support is needed from both sides.

The most effective help which can be offered by government is financial support. The register has to have guaranteed finance and without this it will founder, as shown by the German arthroplasty register. ${ }^{10}$ This was funded from contributions of members and grants from the 
implant industry. After struggling with many organisational problems over a long period, the funding could no longer sustain the running costs and the register was eventually closed down. Other registers, such as the Danish Hip register and the Canadian register also had financial problems in their first year until the national agencies recognised the potential value and subsequently paid the annual costs. ${ }^{4,13}$ The newly-developed registries in Romania, Slovakia and England attached great importance to public financial support from the beginning in order to avoid such experiences.

Federal support can be helpful in other aspects. ${ }^{3}$ The availability of a unique patient identifier, which applies through the whole population is one of the key features contributing to the success in Sweden ${ }^{11,22}$ where patients can be identified by their social security numbers. Other countries use National Health index numbers or civic registration numbers. Registers must be able to easily identify patients undergoing revision operations and to link this data to their primary procedure, even if this was carried out in a different hospital.

However, not every country can rely on these unique patient identifiers because of confidentiality and issues with privacy of data. In Switzerland, the introduction of identification numbers has been put on hold pending the introduction of appropriate laws. As a consequence, their registers have to fall back on nonspecific medical record numbers which do not allow for clear identification of an individual case. In Germany, the failed arthroplasty register also had to use an alternative way to link the cases since the nationwide patient insurance numbers, due to be implemented with the introduction of the electronic health card, were not available during this period. They had to use an encrypted combination of the initials of the patient, the date of birth, the operated side and other details to satisfy the data protection requirements. This complicated the work and the tracing of patients proved nearly impossible.

National patient identifiers can be extremely valuable when validating the fundamental completeness of the data in the registry. The completeness of the data can be checked by comparison with other databases such as the National Institute for Hospital Research in Sweden, ${ }^{23}$ or the National Patient Register in Norway. ${ }^{24}$ It can also be checked by analysis of the local hospital records ${ }^{7}$ or from patients using questionnaires. ${ }^{25}$ Information can be obtained from the manufacturers as to the numbers of implants sold. ${ }^{18}$

Completeness of the national data can be compromised by the need for the patient's consent. In several countries, patients are requested to sign a consent form when their personal details (first name, surname, date of birth, National Health Service (NHS) number, home address, postcode) are stored in the database. In 2003, the English arthroplasty register could obtain patient consent for only for $62.8 \%$ of all procedures entered. ${ }^{26}$ The Canadian regis- ter also struggles with patient consent which is missing from approximately $10 \%$ of forms received. ${ }^{13}$

Federal support is required to enact appropriate laws which make participation obligatory for all hospitals, as is seen in Finland, Slovakia and Denmark. This should lead to an almost complete rate of participation. Refusing to follow such laws could lead to a fine. Hospitals can be encouraged to participate using monetary pressure. In Romania, hospitals which do not fully register all their arthroplasty operations face a reduction in government financial support.

The full support of the national orthopaedic association is necessary, since surgeons bear the major burden of filling out the documentation forms. Their agreement as to the activities of the register, the analyses and the reporting is vital. The Swedish hip register is directed by an independent, professional committee ${ }^{2}$ and ensures the support of the surgeons. When driven by government institutions only, complaints about the lack of orthopaedic influence will arise. In a recent audit, consultants in England doubted that their interests were recognised well enough in the British Joint Registry and they demanded a higher representation on the steering committee. ${ }^{27}$

In the end, it needs the full compliance of all national orthopaedic surgeons to co-operate and agree to reach the highest possible participation rate. ${ }^{11}$

Since both parties profit from having a national arthroplasty register and from sharing the information concerning outcomes, the interests of all have to be respected. An appropriate composition of orthopaedic surgeons and federal representatives on the steering committee has to be found to satisfy everyone's needs. The amount of money which the national health agencies spend on setting up and running a register stands in sharp contrast to the potential savings of a register in the long term. This can be seen from the Scandinavian registers which have shown a considerable financial impact because of a decreased number of revision operations. ${ }^{2,28,29}$ Estimations of potential savings by using a register established in the United States progressing in the same way. ${ }^{3}$ If the revision burden of hip replacements can be decreased by $5 \%$, savings of more than $\$ 30$ million are expected for their general health system. Thus, it is hard to understand why some of the newlydeveloped registers have to struggle to receive their annual budgets.

Documentation. The main goal of every register is to measure the outcome of joint replacement. In order to do so, the revision of an implant is set as the endpoint of failure, calculating the survival rate according to Kaplan-Meier survival analysis. ${ }^{30}$

However, an unrevised prosthesis does not necessarily indicate a good outcome. Many studies have been performed describing this discrepancy between the number of revised patients compared with the failure rate measured either by clinical and radiological scoring systems or by patient-orientated outcome measurements. ${ }^{1,23,31-33}$ There 


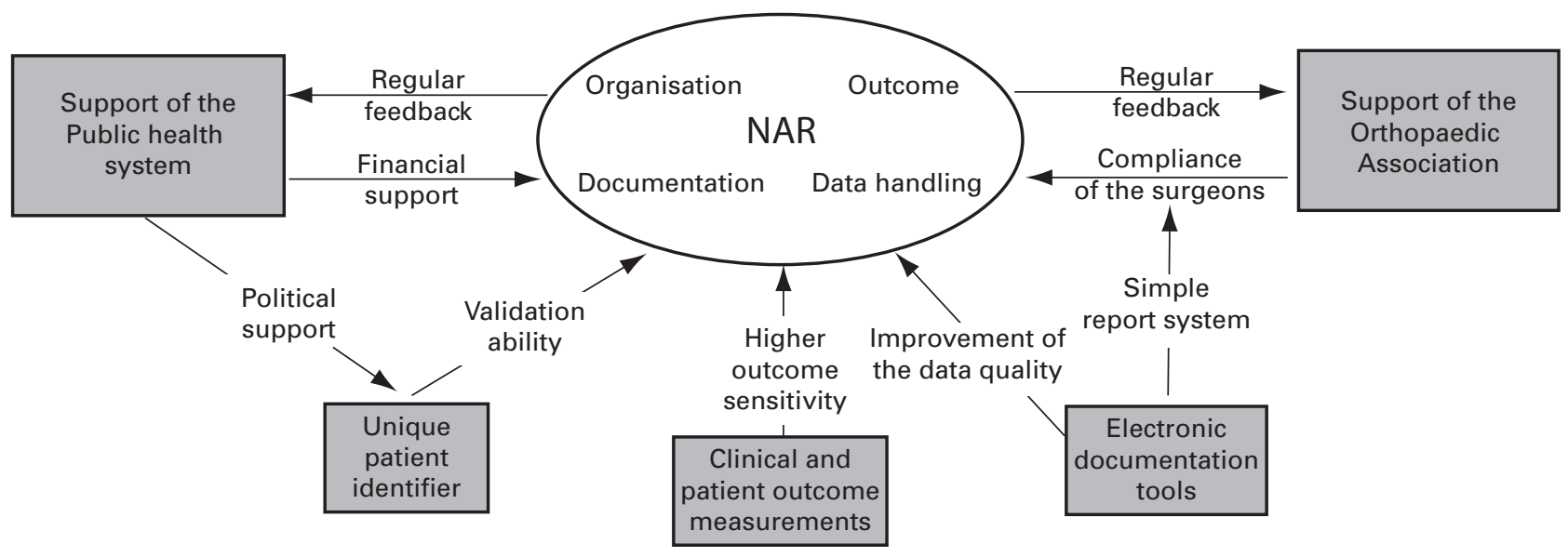

Fig. 2

Chart demonstrating the key factors for a successful national arthroplasty registry (NAR).

are many reasons why revision surgery is not carried out despite significant symptons. ${ }^{33}$ The patient or the surgeon might be unwilling to do the revision because of the age and potential comorbidities of the patient. Long waiting lists might also be responsible for delays in operations. Thus, good survival rates may be described despite many failures. Additional information is needed to assess arthroplasty surgery. Additional information is needed to assess arthroplasty surgery in a more sensitive way. ${ }^{23,34}$ Evaluating the failure rate should make use of soft data with information about pain and function as well as hard data such as revision. ${ }^{35}$ This development has been encouraged in Sweden and the integration of patient-reported outcomes into the Swedish hip register is of high priority. ${ }^{36}$

As this survey shows, many registers have started to implement additional related outcome measurement through patient questionnaires. Self-administered scoring systems, both disease specific and general health-related, have become very popular since patients have been shown to be very co-operative in this field of research. ${ }^{23,25}$ This method seems to be much easier to integrate into a register than collecting information from clinical and radiological analysis. In the early years of the Swedish Knee register, ${ }^{16}$ a clinical evaluation and radiological analysis was performed at certain follow-up times. Later, this was abandoned because of the higher burden of documentation. ${ }^{16}$ This extra workload for clinicians has a negative effect on their compliance and subsequently, the quality of the data suffers.

When collecting data from patient questionnaires or from clinical and radiological information, the handling must be as simple and precise as possible. If the amount of collected information has a negative effect on the completeness and accuracy of data, a smaller but more complete amount is preferable.
Data handling. Different methods are used to handle the data between the registries themselves and between hospitals within the same registry. However, the survey and the information available in the annual reports showed that data is increasingly bring transferred electronically. Now $34 \%$ of hospitals in Denmark ${ }^{37}$ and $70 \%$ in Sweden use this method. ${ }^{38}$ The advantage of electronic documentation is that it allows the integration of completeness and validation checks during the submission of the data. Invalid and incomplete forms are not accepted by the corresponding interface. This guarantees high accuracy and enhances the overall quality. Lost or illogical data can easily be retrieved and monitored.

The data may be exported directly out of the hospital or theatre information system. The minimum data set required for a functional registry is available in the hospital notes, already used for billing purposes. The clinical data then needs only to be entered once, the double entry of information can be prevented and the data is easily traceable. This model of sending the registry data is currently being developed by some registries and is already used in England and Denmark.

The information recorded needs to be precise in order to evaluate each component of the arthroplasty. However, because of the broad variety of implants and their speed of evolution, most documentation forms contain only a simplified list of categories which attempt to summarise all available components, materials or sizes of implants. However, some registers simply enter or scan the implant code or lot number of the implant details at the time of surgery. Afterwards, these numbers can be decoded to enable access to details of the implant, enabling efficient collection of a comprehensive amount of the information.

Nevertheless, paper documentation remains inexpensive and useful and is easily integrated into the workflow of 
hospitals. An improvement is the use of the optimal marker reader scanner that dispenses with keying in by hand.

The Scandinavian registries have shown that high recovery of information is possible with a simple reporting system, even in paper form. ${ }^{15}$ However, the number of arthroplasties has increased over the past decades. ${ }^{2}$ The need for a more precise evaluation of outcome implies that even more information is collected. Hence, a simple but accurate registration system is needed to handle this.

Outcome. When registries are running efficiently, a high completeness of documentation data can be achieved which provides statistically relevant information for many interest groups. Surgeons are the major contributors supplying the register with the fundamental data. Their participation is mostly voluntary and therefore continuous feedback is needed to help motivate and improve their compliance, which again has a positive effect on the quality of the data. The registries, ${ }^{12}$ in turn, offer surgeons a range of services. These generally comprise regular feedback with statistical interpretation of their results and individual information on the quality of the surgery performed locally. In addition, surgeons willing to perform further studies with their own data can be helped by statistical assistance.

The sharing of information on outcomes allows individual hospitals to compare their results with national averages. As a result, units with poor outcomes will improve.

Information concerning outcome needs to be available to the general public. This is made available in annual reports. However, confidentiality has to be guaranteed for the individual surgeon. This is considered as one of the reasons for the success of the Scandinavian registries. ${ }^{15}$ The public exposure of the outcome of surgery is assumed to result in a denial of surgical treatment to high-risk patients. ${ }^{39}$ Another consequence might be a lower compliance of surgeons to fill out the forms correctly. Therefore, most registers publish the results of the hospitals anonymously, although providers of health care are understandably interested in variations of outcome between hospitals.

Registers may also present the results on the performance of individual types of prosthesis and cement in international orthopaedic journals and conferences. It takes some years for registers to gather statistically analysable data, and therefore conclusions presented from recently-developed registers have to be regarded with caution.

Only half of the current registries make their data available to the surgeons. This right should be guaranteed, especially to hospitals which collect the data on paper forms and do not have an electronic file of their outcome measurements. Open access to their own data gives information which can be used for clinical studies within the department.

Summary. A national arthroplasty register can offer a huge benefit to surgeons, manufacturers, those funding health care and to patients. However, several key factors need to be taken into consideration when planning and implementing such a database (Fig. 2). It needs support from the national orthopaedic association and from the government or the public health system. Only then can the appropriate framework be realised. The registries have to be careful when organising documentation. A decision has to be made about the endpoint of failure and whether clinical, radiological or patient data should be included in the outcome measurement. Appropriate tools should be available to make the reporting simple and valid. The data gained can be used in many ways resulting in an overall improvement for patients, surgeons, and providers of health care. ${ }^{13}$

\section{References}

1. Bulstrode C. Total hip replacement: the way forward. Ann $R$ Coll Surg Engl 1996;78:129-32.

2. Herberts $\mathbf{P}$, Malchau H. Long-term registration has improved the quality of hip replacements: a review of the Swedish THR Register comparing 160,000 cases. Acta Orthop Scand 2000;71:111-21

3. Maloney WJ. National Joint Replacement Registries: has the time come? J Bone Joint Surg [Am] 2001;83-A:1582-5.

4. Lucht U. The Danish Hip Arthroplasty Register. Acta Orthop Scand 2000;71:433-9.

5. Graves SE, Davidson D, Ingerson L, et al. The Australian Orthopaedic Association National Joint Replacement Registry. Med J Aust 2004;180(5 Suppl):31-4.

6. Pedersen A, Johnsen S, Overgaard S, et al. Registration in the Danish hip arthroplasty registry: completeness of total hip arthroplasties and positive predictive value of registered diagnosis and postoperative complications. Acta Orthop Scand 2004;75:434-41

7. Arthursson AJ, Furnes O, Espehaug B, Havelin LI, Soreide JA. Validation of data in the Norwegian Arthroplasty Register and the Norwegian Patient Register: 5,134 primary total hip arthroplasties and revisions operated at a single hospital between 1987 and 2003. Acta Orthop 2005;76:823-8.

8. Puolakka TJ, Pajamaki KJ, Halonen PJ, et al. The Finnish Arthroplasty Register: report of the hip register. Acta Orthop Scand 2001;72:433-41.

9. Sharma S, Dreghorn CR. Registry of shoulder arthroplasty: the Scottish experience. Ann R Coll Surg Eng/2006;88:122-6.

10. Pitto RP, Lang I, Kienapfel H, Willert HG. The German Arthroplasty Register. Acta Orthop Scand Supp/ 2002;73:30-3.

11. Malchau H, Herberts P, Eisler T, Garellick G, Soderman P. The Swedish Total Hip Replacement Register. J Bone Joint Surg [Am] 2002;84-A(Suppl 2):2-20.

12. Havelin LI, Engesaeter LB, Espehaug B, et al. The Norwegian Arthroplasty Register: 11 years and 73,000 arthroplasties. Acta Orthop Scand 2000;71:337-53.

13. Bourne RB. The planning and implementation of the Canadian Joint Replacement Registry. Bull Hosp Jt Dis 1999;58:128-32.

14. Rothwell AG. Development of the New Zealand Joint Register. Bull Hosp Jt Dis 1999;58:148-60.

15. Havelin LI. The Norwegian Joint Registry. Bull Hosp Jt Dis 1999;58:139-47.

16. Robertsson O, Dunbar MJ, Knutson K, Lewold S, Lidgren L. The Swedish Knee Arthroplasty Register: 25 years experience. Bull Hosp Jt Dis 1999;58:133-8.

17. Rahme H, Jacobsen MB, Salomonsson B. The Swedish Elbow Arthroplasty Register and the Swedish Shoulder Arthoplasty Register: two new Swedish arthroplasty registers. Act Orthop Scand 2001;72:107-12.

18. Roder C, El-Kerdi A, Frigg A, et al. The Swiss Orthopaedic Registry. Bull Hosp Jt Dis 2005;63:15-19.

19. Lo IK, Griffin S, Kirkley A. The development of a disease-specific quality of life measurement tool for osteoarthritis of the shoulder: the Western Ontario Osteoarthritis of the Shoulder (WOOS) index. Osteoarthritis Cartilage 2001;9:771-8.

20. No authors listed. EQ-5D instrument to describe and value health. http:// www.euroquol.org (date last accessed 20 November 2007).

21. McConnell S, Beaton DE, Bombardier C. THE DASH outcome measure: a user's manual. Toronto, Institute for Work \& Health, 1999.

22. Robertsson 0. Knee arthroplasty registers. J Bone Joint Surg [Br] 2007;89-B:1-4.

23. Soderman $\mathbf{P}$, Malchau H, Herberts P. Outcome after total hip arthroplasty. Part I: general health evaluation in relation to definition of failure in the Swedish National Total Hip Arthroplasty register. Acta Orthop Scand 2000;71:354-9.

24. Espehaug B, Furnes O, Havelin LI, et al. Registration completeness in the Norwegian Arthroplasty Register. Acta Orthop 2006;77:49-56

25. Robertsson 0, Dunbar M, Knutson K, Lewold S, Lidgren L. Validation of the Swedish Knee Arthroplasty Register: a postal survey regarding 30,376 knees operated on between 1975 and 1995. Acta Orthop Scand 1999;70:467-72 
26. No authors listed. National Joint Registry for England and Wales - NJR. 1st Annual Report, 2003. http://www.njrcentre.org.uk (date last accessed 1 March 2007).

27. Philipson MR, Westwood MJ, Geoghegan JM, Henry AP, Jefferiss CD. Shortcomings of the National Joint Registry: a survey of consultant's views. Ann $R$ Coll Surg Eng/ 2005;87:109-12.

28. Herberts P, Malchau H. How outcome studies have changed total hip arthroplasty practices in Sweden. Clin Orthop 1997;344:44-60.

29. Robertsson O, Lewold S, Knutsen K, Lidgren L. The Swedish Knee Arthroplasty Project. Acta Orthop Scand 2000;71:7-18.

30. Kaplan EL, Meier P. Nonparametric estimation from incomplete observations. J Am Stat Assoc 1958;53:457-81.

31. Britton AR, Murray DW, Bulstrode CJ, McPherson K, Denham RA. Pain levels after total hip replacement: their use as endpoints for survival analysis. J Bone Joint Surg [Br] 1997;79-B:93-8.

32. Garellick G, Herberts $\mathbf{P}$, Malchau H. The value of clinical data scoring systems: are traditional hip scoring systems adequate to use in evaluation after total hip surgery? J Arthroplasty 1999:14:1024-9.
33. Soderman $\mathbf{P}$, Malchau $\mathbf{H}$, Herberts $\mathbf{P}$, et al. Outcome after total hip arthroplasty Part II: disease-specific follow-up and the Swedish National Total Hip Arthroplasty Register. Acta Orthop Scand 2001;72:113-19.

34. Malchau H, Herberts $\mathbf{P}$, Ahnfelt L. Prognosis of total hip replacement in Sweden follow-up of 92,675 operations performed 1978-1990. Acta Orthop Scand 1993;64:497-506

35. Soderman P. On the validity of the results from the Swedish National Total Hip Arthroplasty register. Acta Orthop Scand Supp/2000;71:1-33.

36. Malchau H, Garellick G, Eisler T, Karrholm J, Herberts P. Presidential guest address: the Swedish Hip Registry: increasing the sensitivity by patient outcome data. Clin Orthop 2005;441:19-29

37. No authors listed. Danish Hip Arthroplasty Register. Annual Report 2005. http:// www.dhr.dk (date last accessed 22 November 2007).

38. No authors listed. Swedish Hip Arthroplasty Register. Annual Report 2005. http:// www.jru.orthop.gu.se (date last accessed 22 November 2007).

39. Burack JH, Impellizzeri P, Homel P, Cunningham JN Jr. Public reporting of surgical mortality: a survey of New York State cardiothoracic surgeons. Ann Thorac Surg 1999;68:1195-200 